\title{
T2N0 esophageal cancer-We can't know where to go unless we know where we've been
}

\author{
Matthew Fox, MD
}

\author{
From the Department of Cardiovascular and Thoracic Surgery, University of Louisville, Louisville, Ky. \\ Disclosures: Author has nothing to disclose with regard to commercial support. \\ Received for publication Nov 12, 2018; accepted for publication Nov 13, 2018; available ahead of print Dec 28, \\ 2018. \\ Address for reprints: Matthew Fox, MD, Department of Cardiovascular and Thoracic Surgery, University of \\ Louisville, 201 Abraham Flexner Way, Suite 1200, Louisville, KY 40202 (E-mail: Matthew.fox@ulp.org). \\ J Thorac Cardiovasc Surg 2019;157:1273-4 \\ $0022-5223 / \$ 36.00$ \\ Copyright (C) 2018 by The American Association for Thoracic Surgery \\ https://doi.org/10.1016/j.jtcvs.2018.11.048
}

An old English proverb of unknown origin states "You don't know where you're going unless you know where you've been.' Unfortunately, the controversy regarding the treatment of T2N0 esophageal carcinoma stems from such a predicament. It has been well documented that despite advances in staging with endoscopic ultrasound and positron emission tomography/computed tomography (CT), the majority of patients with T2N0 esophageal carcinoma are either overstaged, approximately $20 \%$ to $30 \%$, or understaged, approximately $40 \%$ to $55 \%$, with $40 \%$ to $50 \%$ of patients having positive lymph nodes at esophagectomy. ${ }^{1,2}$ This carries major implications for treatment, as neoadjuvant therapy is associated with morbidity, and evidence exists showing patients with surprise T3 or nodal disease do poorly after upfront esophagectomy. ${ }^{3}$

Some groups have postulated that given the propensity for understaging, T2N0 patients should receive neoadjuvant treatment, ${ }^{4,5}$ and in a recent paper Semenkovich and colleagues $^{6}$ used formal decision analysis to suggest a benefit to neoadjuvant therapy in T2N0 patients with risks factors (length $>3 \mathrm{~cm}$, lymphovascular invasion, high grade). Unfortunately, no randomized trial exists that verifies this hypothesis. The ChemoRadiotherapy for Oesophageal cancer followed by Surgery Study (CROSS) trial contained few patients with T2N0 and the FFCD 9901 trial's perioperative mortality of $11.1 \%{ }^{7}$ in the neoadjuvant group render its results suspect when contemporary centers of excellence claim mortality rates of $1 \%$ to $2 \%$ in large series. Retrospective studies both with large databases and local data have shown both survival advantages and no difference with neoadjuvant therapy. ${ }^{8-10}$

The authors present a relatively large series of 767 patients from 15 high-volume institutions that show no survival advantage with neoadjuvant chemotherapy or chemoradiotherapy in an unselected T2N0 cohort. Although the authors should be commended for a well-written and thoughtful paper, the study does fall prey to some of the traps of registry studies. Notably, staging methods were not standardized, actually have it.

\section{References} 382-90.

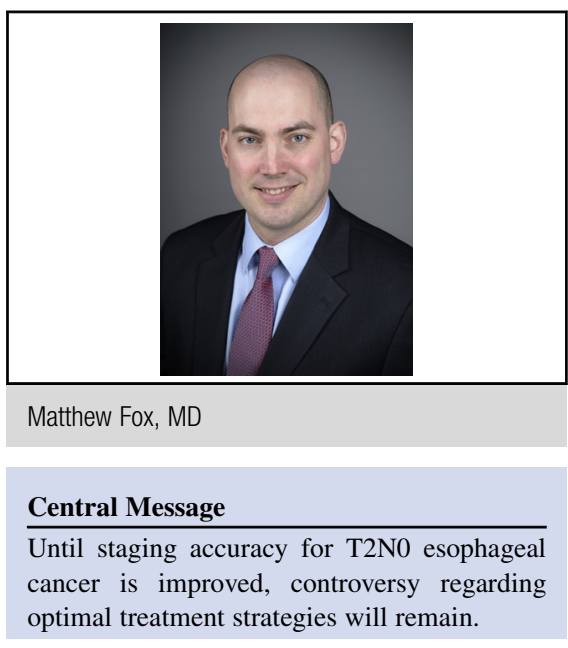

See Article page 1264 .

and only $42.8 \%$ and $49.1 \%$ of patients definitively had a positron emission tomography/CT and endoscopic ultrasound, respectively. Given the relatively poor ability of CT to distinguish $\mathrm{T}$ stage, these results should be viewed skeptically, as an unknown proportion of stage I cancers may have biased the study toward the null. The authors also show that tumor length and lymphovascular invasion are risk for factors for nodal disease, but no survival benefit was seen with neoadjuvant therapy even in these high-risk patients. Given the proven benefit of neoadjuvant therapy in the T3 or greater and node positive esophageal cancer cohort, this suggests that the cited indirect risk factors for this pathology, namely tumor length and lymphovascular invasion, are still inadequate to guide therapy.

The ongoing controversy over the best treatment for T2N0 patients suggests that new technology is needed to improve staging accuracy. Whether this comes from improved endoscopic ultrasound techniques such as highfrequency probes or elastography or improved molecular methods of staging, it will be impossible to settle the argument on what the best treatment algorithm is for patients with T2N0 disease until we confidently say which patients

1. Crabtree TD, Kosinski AS, Puri V, Burfeind W, Bharat A, Patterson GA, et al. Evaluation of the reliability of clinical staging of T2 N0 esophageal cancer: a review of the Society of Thoracic Surgeons database. Ann Thorac Surg. 2013;96: 
2. Dolan JP, Kaur T, Diggs BS, Luna RA, Sheppard BC, Schipper PH, et al. Significant understaging is seen in clinically staged T2N0 esophageal cancer patients undergoing esophagectomy. Dis Esophagus. 2016;29:320-5.

3. Samson P, Puri V, Robinson C, Lockhart C, Carpenter D, Broderick S, et al. Clin ical T2N0 esophageal cancer: identifying pretreatment characteristics associated with pathologic upstaging and the potential role for induction therapy. Ann Thorac Surg. 2016;101:2102-11.

4. Zhang JQ, Hooker CM, Brock MV, Shin J, Lee S, How R, et al. Neoadjuvant chemoradiation therapy is beneficial for clinical stage T2 N0 esophageal cancer patients due to inaccurate preoperative staging. Ann Thorac Surg. 2012;93:429-35; discussion 36-7.

5. Hardacker TJ, Ceppa D, Okereke I, Rieger KM, Jalal SI, LeBlanc JK, et al. Treatment of clinical T2N0M0 esophageal cancer. Ann Surg Oncol. 2014;21:3739-43.

6. Semenkovich TR, Panni RZ, Hudson JL, Thomas T, Elmore LC, Chang SH, et al. Comparative effectiveness of upfront esophagectomy versus induction chemora- diation in clinical stage T2N0 esophageal cancer: a decision analysis. $J$ Thorac Cardiovasc Surg. 2018;155:2221-30.e1.

7. Mariette C, Dahan L, Mornex F, Maillard E, Thomas PA, Meunier B, et al. Surgery alone versus chemoradiotherapy followed by surgery for stage I and II esophageal cancer: final analysis of randomized controlled phase III TRIAL FFCD 9901. J Clin Oncol. 2014;32:2416-22.

8. Goense L, Visser E, Haj Mohammad N, Mook S, Verhoeven RHA, Meijer GJ, et al. Role of neoadjuvant chemoradiotherapy in clinical T2N0M0 esophageal cancer: a population-based cohort study. Eur J Surg Oncol. 2018;44:620-5.

9. Markar SR, Gronnier C, Pasquer A, Duhamel A, Beal H, Théreaux J, et al. Role of neoadjuvant treatment in clinical T2N0M0 oesophageal cancer: results from a retrospective multi-center European study. Eur J Cancer. 2016;56:59-68.

10. Speicher PJ, Ganapathi AM, Englum BR, Hartwig MG, Onaitis MW, D'Amico TA, et al. Induction therapy does not improve survival for clinical stage T2N0 esophageal cancer. J Thorac Oncol. 2014;9:1195-201. 